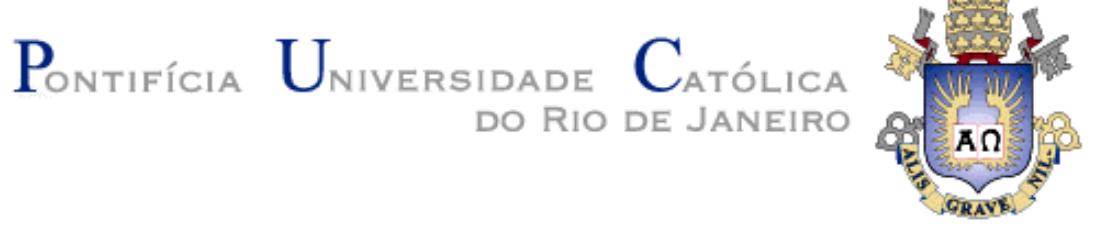

Pedro Rocha de Oliveira

Dialética Negativa como perspectiva para o pensamento

Dissertação de Mestrado

Dissertação apresentada ao Programa de PósGraduação em Filosofia da PUC-Rio como requisito parcial para obtenção do título de Mestre em Filosofia.

Orientador: Edgard José Jorge Filho

Rio de Janeiro, fevereiro de 2005 


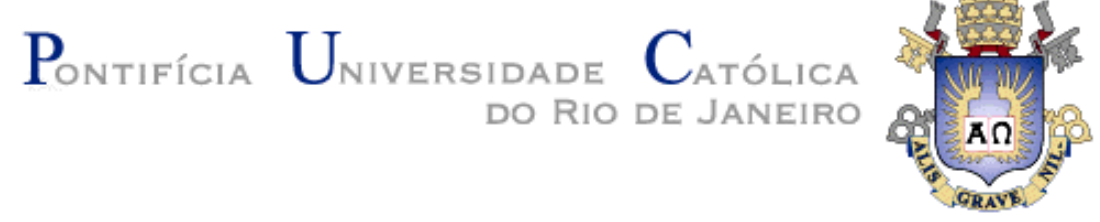

Pedro Rocha de Oliveira

\title{
Dialética negativa como perspectiva para o pensamento
}

Dissertação apresentada como requisito parcial para obtenção do título de Mestre pelo Programa de PósGraduação em Filosofia do Departamento de Filosofia do Centro de Teologia e Ciências Humanas da PUCRio. Aprovada pela Comissão Examinadora abaixo assinada.

\author{
Prof. Edgard José Jorge Filho \\ (Orientador) \\ Departamento de Filosofia - PUC-Rio \\ Profa. Vera Cristina de Andrade Bueno \\ Departamento de Filosofia - PUC-Rio
}

Prof. Luiz Eduardo de Oliveira Bicca Departamento de Filosofia -

Prof. Paulo Fernando Carneiro de Andrade Coordenador Setoria do Centro de Teologia e Ciências Humanas - PUC-Rio 
Todos os direitos reservados. É proibida a reprodução total ou parcial do trabalho sem autorização da universidade, do autor e do orientador.

\section{Pedro Rocha de Oliveira}

Graduou-se em Filosofia na Universidade do Estado do Rio de Janeiro em 2003, tendo realizado duas pesquisas de iniciação científica, a primeira sobre a metafísica de Spinoza e a segunda sobre a crítica de Hegel à teoria do conhecimento moderna. Atualmente, estuda tópicos de filosofia da cultura e filosofia política problematizados à luz do pensamento da Escola de Frankfurt.

Ficha Catalográfica

Oliveira, Pedro Rocha de

Dialética negativa como perspectiva para o pensamento / Pedro Rocha de Oliveira ; orientador: Edgard José Jorge Filho. - Rio de Janeiro : PUC-Rio, Departamento de Filosofia, 2005.

230 f. ; $30 \mathrm{~cm}$

Dissertação (mestrado) - Pontifícia Universidade Católica do Rio de Janeiro, Departamento de Filosofia.

Inclui referências bibliográficas

1. Filosofia - Teses. 2. Adorno, Theodro W., 19031969. 3. Hegel, Georg Friedrich, 1770-1831. 4. Dialética do esclarecimento. 5. Dialética negativa. I. Jorge Filho, Edgard José. II. Pontifícia Universidade Católica do Rio de Janeiro. Departamento de Filosofia. III. Título. 


\section{Agradecimentos}

Ao meu orientador, Professor Edgard José Jorge Filho, pelo estímulo e pela confiança - os quais resultaram em uma liberdade intelectual que muito beneficiou meu desenvolvimento acadêmico -, e também pela atenção e seriedade com que se debruçou sobre meus trabalhos e pôs à minha disposição seus conhecimentos.

À professor Vera Cristina de Andrade Bueno, pela disponibilidade para dialogar, pelo rigor e generosidade com que sempre encarou meus questionamentos, por sua preocupação e carinho.

Ao professor Luiz Bicca, por ter me apresentado ao pensamento de Adorno, pelo encorajamento e amizade, pelo suprimento regular de geléias.

A Mônica e Barbara, pela paciência e amorosidade com que sempre respeitaram minhas necessidades de silêncio e reclusão, e também pelas numerosas contribuições e interferências em meus questionamentos.

Ao meu pai, de quem herdei o espírito crítico que anima meus estudos.

Ao $\mathrm{CNPq}$, pela bolsa que recebi no segundo ano de meu mestrado, e por meio da qual consegui completar esta etapa de meus estudos com tranqüilidade e satisfação. 


\section{Resumo}

Oliveira, Pedro Rocha de; Jorge Filho, Edgard José. Dialética Negativa como perspectiva para o pensamento. Rio de Janeiro, 2004. 222p. Dissertação de Mestrado - Departamento de Filosofia, Pontifícia Universidade Católica do Rio de Janeiro.

A partir da caracterização geral do pensamento ocidental como "esclarecido", desenvolvida por Adorno e Horkheimer na Dialética do Esclarecimento, a Dialética Negativa de Adorno é apresentada, nesta Dissertação, como a expressão do "modo de pensar" adorniano. O pensamento esclarecido é tratado em função das características utilizadas por Adorno para defini-lo como "sistemático". Enquanto anteposição ao pensamento sistemático, o modo de pensar adorniano, portanto, não é ele mesmo um sistema de pensamento, mas uma disciplina que procura questionar a preocupação do pensamento exclusivamente ou principalmente com sua própria coerência interna, preocupação esta que se dá em prejuízo do seu contato com o real. Nesta Dissertação, a apresentação do modo de proceder desta disciplina - a Dialética Negativa -, é preparada por uma análise do Górgias de Platão, e do Fé e Saber e da Fenomenologia do Espírito de Hegel, análise esta que, procurando os objetos em função dos quais a argumentação destes textos é construída, critica a indiferença com relação ao real praticada por estes autores, e sua afirmação de uma certa onipotência do pensamento.

\section{Palavras-chave}

Theodor W. Adorno; G. W. F. Hegel; Dialética do Esclarecimento; Dialética Negativa. 


\section{Abstract}

Oliveira, Pedro Rocha de; Jorge Filho, Edgard José (Advisor). Negative

Dialectics as a prospect for thought. Rio de Janeiro, 2004. 222p. MA. Dissertation - Philosophy Department, Pontifícia Universidade Católica do Rio de Janeiro.

Proceeding from the general characterization "enlightened" thought developed by Adorno and Horkheimer in their Dialectics of Enlightenment, Adorno's Negative Dialectic is presented as the expression of the adornian "way of thinking". Enlightened thought is dealt with on the basis of those characteristics employed by Adorno to define it as "systematic". As an alternative to systematic thought, the adornian way of thinking, therefore, is not itself a system, but a discipline that seeks to dispute thought's traditional preocupation with its own internal consistency, whose consequences are much to the prejudice of thought's contact with reality. The present dissertation thus aims at an exposition of this discipline's way of proceeding, but such exposition is prepared by analyses of Plato's Gorgias and of Hegel's Faith and Knowledge and Phenomenology of Spirit. By looking for the objects behind those texts' argumentative consistence, those analyses criticize the indiference towards reality practiced by those authors, and brings to light their questionable affirmation of the omnipotency of thinking.

\section{Keywords}

Theodor W. Adorno; G. W. F. Hegel; Dialectics of Enlightenment; Negative Dialectics. 


\section{Sumário}

1. Introdução

2. A ordem e seu contrário 22

2.1. Sócrates-Górgias: do ser ao interesse. 25

2.2. Sócrates-Pólo: a ordem e o tolo 36

2.3. Sócrates-Cálicles: a violência como uma outra face da ordem. 56

2.4. Conclusão da Análise do Górgias. 66

3. Pensamento esclarecido moderno 70

3.1. Estudo da Introdução ao Fé e Saber de Hegel 83

3.2. O modelo hegeliano de consciência 114

4. Dialética Negativa como perspectiva para o pensamento 181

$\begin{array}{ll}\text { Bibliografia } & 226\end{array}$ 


\section{Nota sobre as citações}

As citações às obras da bibliografia principal, cujo esforço de análise resultou na maior parte do conteúdo desta dissertação, foram feitas no corpo do texto, entre parênteses, e utilizando as seguintes abreviaturas, seguidas do número da página, do número do parágrafo, no caso da Fenomenologia do Espírito, da paginação padrão, no caso da Crítica da Razão Pura, ou, para as demais obras, da paginação das edições indicadas em minha Bibliografia:

$$
\begin{aligned}
& \text { FS - Fé e Saber } \\
& \text { FE - Fenomenologia do Espírito } \\
& \text { DN - Dialétia Negativa } \\
& \text { DE - Dialética do Esclarecimento } \\
& \text { CRP - Crítica da Razão Pura }
\end{aligned}
$$

Optei por abreviaturas ao título da obra em português para tornar mais imediato o deciframento das notas, ainda que nem o Fé e Saber (Glauben un Wissen, 1802) de Hegel, nem a Dialética Negativa (Negative Dialektik, 1966) de Adorno, possuam tradução para nosso idioma. Para o primeiro, utilizei a tradução para língua inglesa de Harris e Cerf; para o segundo, utilizei primordialmente a tradução também para língua inglesa de E. B. Ashton, a qual, no entanto, é reconhecida por diversos comentadores como problemática e, muitas vezes, terrivelmente equivocada. Em virtude disso, cotejei o texto da tradução de Ashton com a tradução americana de Redmond (disponível apenas em meio digital), com a tradução italiana de Donolo e também, em algumas passagens que me pareciam especialmente delicadas, com o original em alemão. A paginação oferecida, aliás, refere-se à edição das obras completas pela Suhrkamp Verlag, e acompanha, às vezes, o título dos fragmentos segundo a tradução de Ashton, o que, espero, ajude a localização, nesta e em outras traduções, dos trechos citados.

As citações à Fenomenologia do Espírito foram montadas a partir das três traduções indicadas na Bibliografia: a brasileira, de Paulo Meneses, a francesa, de Jean Hyppolite, e a inglesa, de Arnold Miller. Esta montagem não visou corrigir qualquer das traduções empregadas, mas sim tornar o texto excepcionamente 
complicado de Hegel o mais inteligível possível ao leitor que não está familiarizado com seu estilo. Além disso, tal procedimento talvez também ofereça ao leitor a chance de ler com os meus olhos, uma vez que minha interpretação do texto hegeliano está essencialmente condicionada pela apreensão através destas três traduções, conjuntamente.

Quanto ao Górgias de Platão, cuja análise ocupa o Capítulo 1 deste trabalho, fiz as referências unicamente evocando a paginação padrão da obra de Platão, entre parênteses, no corpo do texto, sem utilizar abreviatura, o que não causará confusão, pois tais citações se restringem ao Capítulo 1.

As demais obras foram citadas através de notas de rodapé. 